\title{
THERMAL-PHYSICAL PECULIARITIES OF GAS-SHIELDED PULSE-ARC WELDING USING NON-CONSUMABLE ELECTRODE (Review)
}

\author{
A.A. SLIVINSKY, L.A. ZHDANOV and V.V. KOROTENKO \\ NTUU «Kiev Polytechnic Institute» \\ 37 Pobeda Ave., 03056, Kiev, Ukraine. E-mail: o.slyvinsky@gmail.com
}

\begin{abstract}
The work studies the main problems of development and possible perspectives for further improvement of inert-gas non-consumable pulse-arc welding. Main technological possibilities and thermal-physical peculiarities of the process are given depending on variation of welding mode parameters. Considered are the directions for development of methods of mathematical modeling of welding process and possible ways of their improvement. Necessity in further investigations of the process for determination of parametric dependencies and development for engineering and scientific purposes of optimum modes of pulse-arc welding using tungsten cathode was grounded. 41 Ref., 7 Figures.
\end{abstract}

Keywords: pulse TIG welding, thermal cycles, mode rigidity, gas-dynamic characteristics, transition processes, discretization, precision, thermocouple, finite element method.

TIG welding starts active development in period of aircraft and space engineering, namely in the 1960s of the last century. Today TIG welding is one of the most wide-spread methods for joining of metals and alloys. It is widely used in industry branches with high requirements to welds and structures, particularly in aircraft and rocket production [1-6].

Equipment for alternating current welding with pile-up of pulses for aluminum joining was developed till the end of 1960s. It was based on mechanical contactors and performed nonconsumable pulse-arc welding. At that, lowamperage stationary arc was kept between the pulses, that allowed for significant process stabilization and increase of welded joint quality [7-9].

Development of TIG welding together with application of different consumables and auxiliary materials (fluxes, pastes, filler wires and gas mixtures) is based on methods and means of change of process energy characteristics, that provides for efficient influence on heat input in welding [10]. Thus, in proper time application was found for such methods of welding as step-arc welding [11] and modulated current welding [12].

Further development of element base, power electronics as well as microprocessor and digital equipment resulted in expansion of amount of controlled values and regulated parameters of the mode. It is $7-10$ for pulse-arc welding in

(C) A.A. SLIVINSKY, L.A. ZHDANOV and V.V. KOROTENKO, 2015 modern current power sources. At that, pulse current $\left(I_{\mathrm{p}}\right)$, break current $\left(I_{\mathrm{b}}\right)$, duration of pulse $\left(t_{\mathrm{p}}\right)$ and breaks $\left(t_{\mathrm{b}}\right)$, time of pulse growth $\left(t_{\mathrm{up}}\right)$ and time of pulse drop $\left(t_{\text {down }}\right)$ and shape of pulse have direct effect on peculiarities of existence of arc discharge. Arc voltage is set by length of inter-arc gap, i.e. set by operator.

Obviously that correct selection of welding mode is a complex and long process. Therefore, synergetic power sources, in which a program sets the optimum relationship of parameters of mode in the power source, find more and more application at current time. In order to receive corresponding software program, providing necessary mode of power source, an operator shall set material, its thickness, electrode diameter, welding position and welding current (stationary or pulse mode). At that, application of advanced computer technologies using PC and communication technologies, namely Ethernet and $\mathrm{WiFi}$, are provided for easy selection of welding mode parameters. Development of PC-welding power source systems has already allowed tracing all parameters of welding mode as well as carrying their analysis and adjustment in automatic mode directly via software set on PC (ewm Xnet technology) [13] from EWM and Fronius Digital Revolution [14]).

Number of investigations was carried out and large amount of welding equipment with different capabilities was developed from the appearance of non-consumable pulse welding up to present moment. However, large number of parameters of welding mode regulation complicates its selection and designation for specific task. It is 
particularly relevant for sheet metal, where increase of efficiency is important, but formation of burning through and significant deformation of structure shall not be allowed. Modern advanced technologies of regulation of process of pulsed-current argon-gas tungsten-electrode arc welding (PTIGW) do not always allow achieving optimum result, first of all, due to large set of process regulated parameters and their relationships. Therefore, investigation of their effect on geometry of welded joint, which depends on weld pool shape and being determined by physical characteristics of plasma of arc discharge, is still relevant task.

Balance between efficiency and quality of welded joint is to be kept in welding of sheet metal. Heat supply in pulse mode input allows significant expansion of possibilities of regulation of heat input into base metal and its penetration. In general, base metal penetration and weld formation can be represented using the following scheme.

Input of heat $Q$ takes place in course of current pulse of $t_{\mathrm{p}}$ duration. It provokes melting of base metal with formation of weld pool in form of point $Q=q_{\mathrm{a}} t_{\mathrm{p}}$, where $q_{\mathrm{a}}$ is the arc effective power, and $t_{\mathrm{p}}$ is the duration of pulse of principle current. The weld pool is cooled till complete or partial solidification in course of $t_{\mathrm{b}}$. The next heat pulse will melt the same spot weld pool at $S=v\left(t_{\mathrm{p}}+t_{\mathrm{b}}\right)$ distance from previous point, where $v$ is the welding speed.

In such a way, the weld is formed by means of periodical melting of separate points with set step $S$. Level of points overlapping is determined by their size and step. Amount of heat per unit of weld length makes $Q / S=q_{\mathrm{a}} t_{\mathrm{p}} / v\left(t_{\mathrm{p}}+t_{\mathrm{b}}\right)$, where $q_{\mathrm{a}} t_{\mathrm{p}} / t_{\mathrm{p}}+t_{\mathrm{b}}$ is the average power of periodic arc.

Study [15] shows that process of pulse arc welding to a first approximation can be considered as welding process with direct current arc of $q_{\mathrm{r}} / q_{\mathrm{a}}\left(1+t_{\mathrm{b}} / t_{\mathrm{p}}\right)$ power. Calculated current at that makes $I_{\mathrm{r}}=I_{\mathrm{p}} /\left(1+t_{\mathrm{b}} / t_{\mathrm{p}}\right)$. Relationship $t_{\mathrm{b}} / t_{\mathrm{p}}$ characterizes current frequency and stipulates penetration ability of periodic arc. The greater it is at the same calculated current $I_{\mathrm{r}}$ (average power), the more pulse current (pulse power) is. Dimensionless $t_{\mathrm{b}} / t_{\mathrm{p}}$ value is a technological parameter characterizing ability to penetration of periodic (pulse) arc at set pulse energy and cycle duration. It is called rigidity of mode of pulse arc welding $(G)$.

Thus, pulse arc penetration ability can be effected by change of mode rigidity and absence of variation in current value. Comparative inves-

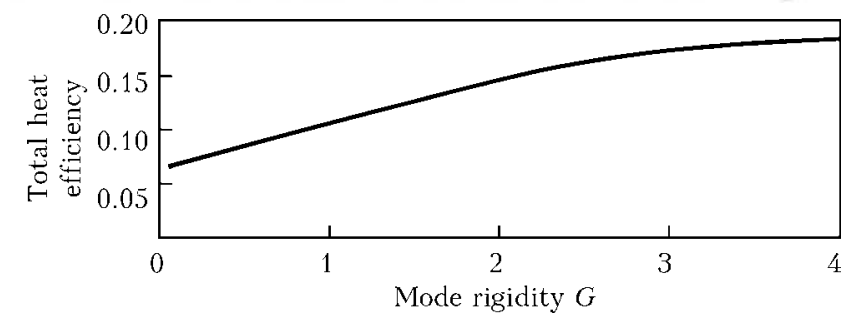

Figure 1. Mode rigidity versus total heat efficiency [15]

tigations on stationary and pulse arc welding of $3 \mathrm{~mm}$ thick 12Kh18N9T steel, given in [15], showed that increase of rigidity promotes for rise of value of total heat efficiency (Figure 1) under conditions of equal average rate of heat input and welding speed.

The attention is also paid to the fact [15] that increase of $G$ under condition of similar penetration provides for reduction of zones of plastic deformations (heating above $600{ }^{\circ} \mathrm{C}$ ) (Figure 2).

Work [16] according to the results of measurement of thermal cycles showed that rise of mode rigidity at the same currents significantly reduces HAZ (temperature in test points being at $2 \mathrm{~mm}$ distance from welding axis decreased per $200{ }^{\circ} \mathrm{C}$ at rise of $G$ from 0.3 to 3 ). The results published in [17] (Figure 3) verify this. Thus, it can be stated that mode rigidity has decisive effect on form of welding thermal cycles and time of weld pool existence and can serve as general integral parameter of PTIGW process.

Studying PTIGW processes, in addition to time characteristic of pulses, requires outlining such parameters of modes as pulse current $\left(I_{\mathrm{p}}\right)$, base current value $\left(I_{\mathrm{b}}\right)$ and welding speed $(v)$, which determine a rate of energy input. If $I_{\mathrm{p}}$ is the parameter, first of all, effecting the base metal penetration, then $I_{\mathrm{b}}$, according to [18], is used for stabilizing arc discharge. Thus, $I_{\mathrm{b}}$ zero value promotes for rise of possibility of so-called erratic arc, that results in undetermined location of areas of arc excitation on electrode and reduces arc process stability.

Another peculiarity of PTIGW is deformation of shape of arc discharge with possible lagging of anode spot. Author of study [19] explains this

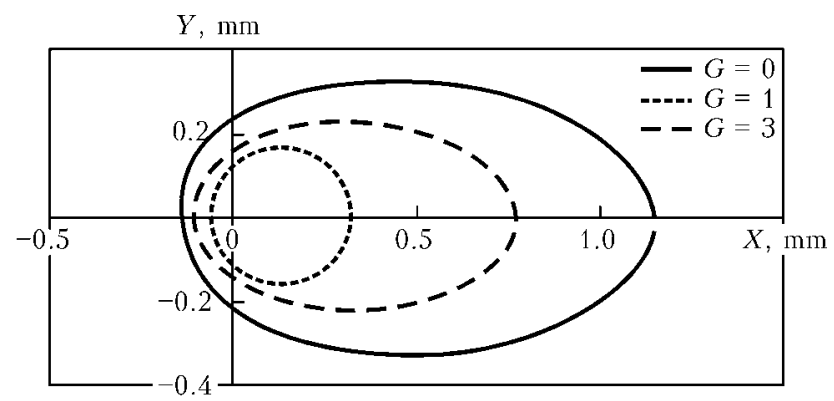

Figure 2. Calculation isotherms $T=600{ }^{\circ} \mathrm{C}$ at different modes of welding using pulsed and stationary arc [15] 
$T,{ }^{\circ} \mathrm{C}$

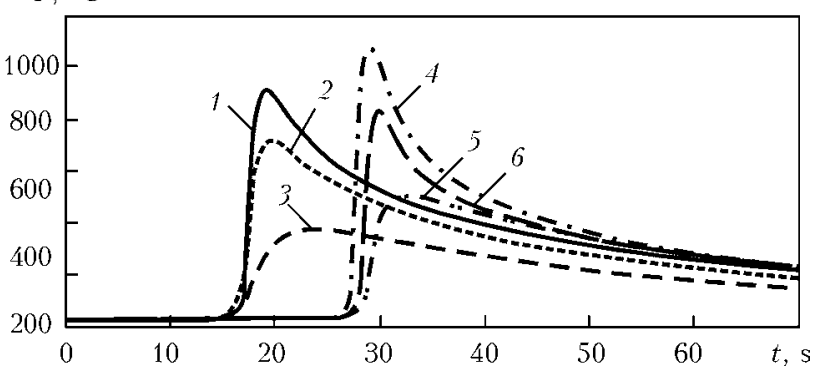

Figure 3. Thermal cycles measured in welding with pulsed $(1-3)$ and stationary (4-6) arc for points at 4, 6 and $8 \mathrm{~mm}$ distance from weld axis [17]

effect by the fact that evaporation of base metal, taking place during current pulse, supplies to arc discharge the atoms of lower ionizing potential than that of shielding gas atoms, but simultaneously promotes for decrease of level of heat contraction of arc column, that, in turn, results in high values of voltage drop during the break. This generates contradiction between available favorable conditions of arc existence on weld metal melted by current pulse and necessity of its movement in less favorable conditions of cold metal.

Based on principle of Steenbeck thermodynamic minimum [20], lags of anode spot shall appear on molten metal from time to time in processes of welding, since the molten metal provides for minimum arc voltage. The anode spot moves synchronously with molten metal pool, lagging from electrode movement before voltage of stretched arc do not become equal to anode process excitation voltage. Due to this arc movement can be of stepwise nature. Such a lag of anode spot results in significant for oscillation of arc voltage per 10-15 $\mathrm{V}$ [21], that, in turn, provokes oscillations of heat power and as a consequence unstable base metal penetration.

Thus, it can be noted that spatial instability of moving arc significantly limits area of allowable parameters of welding mode. Therefore, supporting of arc column ionizing requires keeping some arc current before the next pulse within the

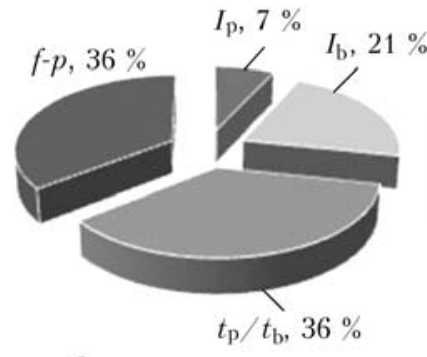

$a$

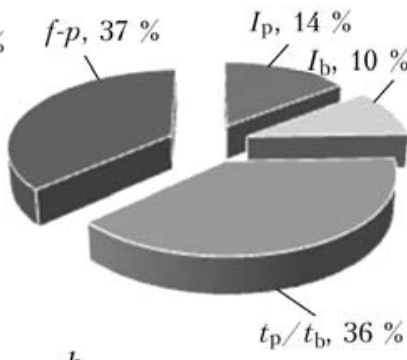

$b$ time gaps between pulses. Thus, stability of PTIGW process can be reached namely with the help correct selection of base current value, keeping arc column ionization, and frequency of pulses.

A great deal of current investigations [22-25] is dedicated to selection of optimum parameters. Quantitative verification of investigations is represented in overwhelming majority by mathematical dependencies being received using Taguchi method. Effect of parameters of mode of pulse-arc welding on base metal penetration for the range of current pulsing frequency up to 10 (PTIGW) and 100-250 Hz (HF-PTIGW) was evaluated in [26] by given procedure. It can be seen from diagram (Figure 4) that $t_{\mathrm{p}} / t_{\mathrm{b}}$ relationship (value reverse to mode rigidity) and current pulsing frequency $f-p$ have the main effect on process of penetration and formation of welded joint in PTIGW as well as HF-PTIGW. At the same time, such parameters of mode as base and pulse currents have the least effect on penetration. However, these are the parameters influencing welding process stability and, respectively, quality of welded joint formation.

There is a great deal of works dedicated to PTIGW process simulation. At that, physicalmathematical modeling of characteristics of arc pulse discharge is usually a basis for experimental data, received with the help of arc sounding method [27, 28].

Results of mathematical modeling of arc discharge between tungsten cathode and copper water-cooled anode, given in [29], showed that existence of arc discharge in welding using pulseperiodic mode is accompanied by significant changes of electromagnetic, thermal and gas dynamic characteristics of arc plasma.

Presented results of simulation show that transition processes play an important role in heat input distribution over the base metal. Their experimental investigation can be carried out based on analysis of electron oscillograms of energy parameters of arc discharge, i.e. current and voltage.

Selection of characteristics of primary probes and registration devices, namely analog-digital transducers (ADT), is very important when performing such oscillographic testing. Procedure on selection of the primary probes for generation of suitable digital signal image is described in details in work [30], and principles of selection of ADT for oscillographic testing are given in [31].

Current approaches to simulation of physical processes, taking place in arc discharge plasma during PTIGW, described in works [32-36], provides for application of finite element method
Figure 4. Diagrams of distribution of effect of main parameters of PTIGW $(a)$ and HF-PTIGW $(b)$ on base metal penetration [26] 

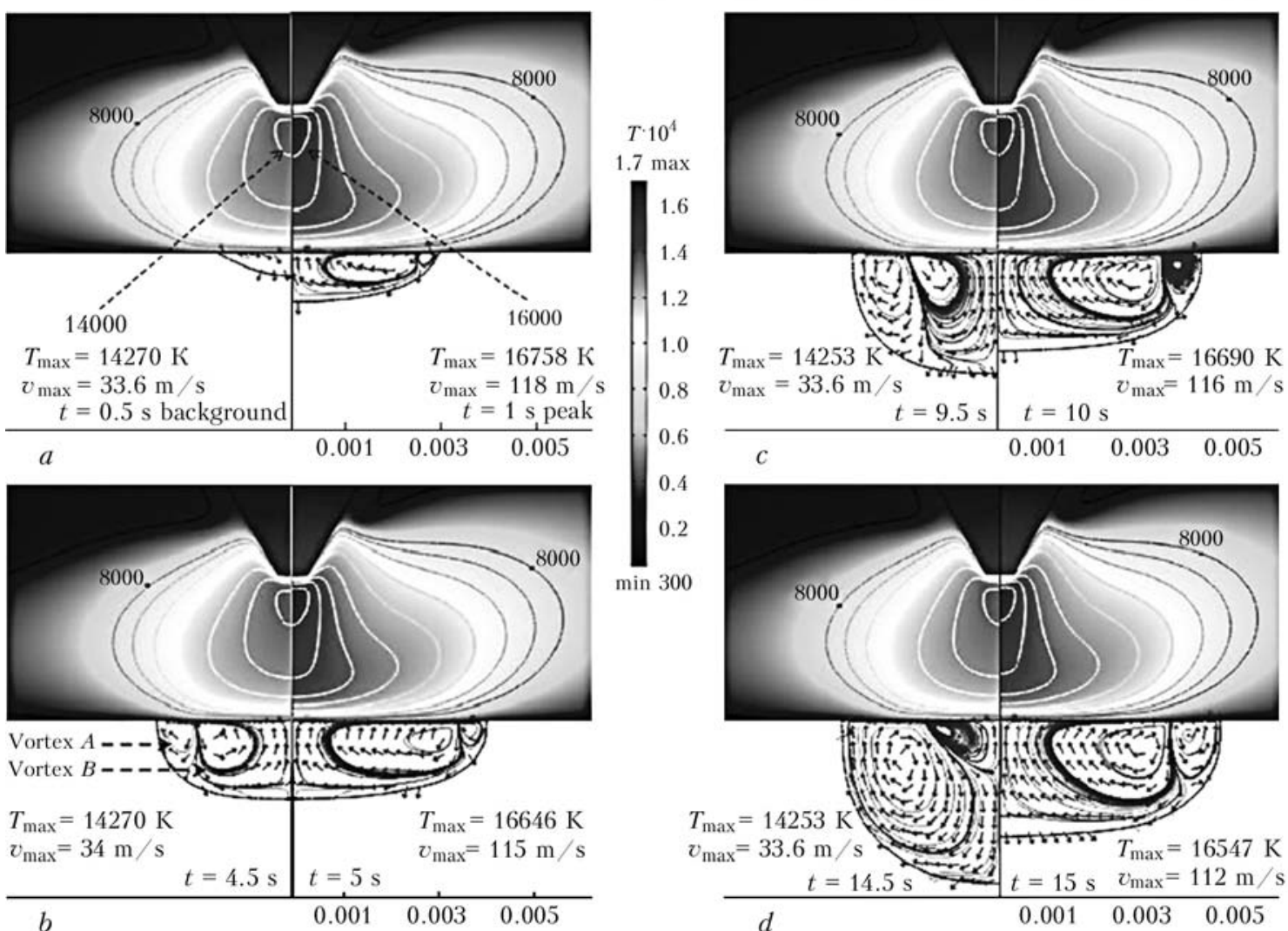

Figure 5. Results of simulation of magnetic-hydro-dynamic processes in weld pool for periods of effect of base current (left) and pulse current (right) at time moment of $1(a), 5(b), 10(c)$ and $15(d)$ s from the PTIGW beginning at $I_{\mathrm{p}}=$ $=160 \mathrm{~A}, I_{\mathrm{b}}=80 \mathrm{~A}$ and $f-p=1 \mathrm{~Hz}$ [36]

(FEM). Thus, results, received in [36], are based on application of infra-red chamber and numerical FEM-simulation using ComsolScript complex. At that, calculation of temperature distribution in cathode and anode area and in plasma arc is carried out using a system of main classic Maxwell's equations. Simulation of magnetichydro-dynamic processes showed that different various take place in weld pool at different moments of time and they significantly depend on electrodynamic characteristics of plasma column as well as its temperature (Figure 5).

It was determined that the maximum temperature of tungsten cathode made $3500 \mathrm{~K}$ in pulse moment and $3200 \mathrm{~K}$ at break moment. The maximum temperature of plasma area was $14250 \mathrm{~K}$ in break moment and $16540 \mathrm{~K}$ at pulse current effect. It is the well-known fact that these values significantly depend on material of anode, value of welding current and distance between the electrodes. Results of calculation also show nature of change of penetration depth and width depending on amount of pulses at the same point of metal. This allows talking about heat saturation depending on amount of pulses (Figure 6).

The main thesis of results presented in [36] is a statement of authors that no change of shape takes place in cross-section of the weld pool in pulse arc welding even at significant difference in base and pulse values of current, that allows for regulating these parameters in a wide range during sheet metal welding. At the same time, this work assumed the following simplifications during simulation, namely thermodynamic equilibrium takes place in arc plasma, and effect of metal vapors is not considered. The latter assumption significantly reduces efficiency of application of this model on practice. In general case, it should be noted that the model is designed for spot welding, i.e. when power source is stationary. This also introduces significant errors in prediction of base metal penetration.

It is the well-known fact that structural transformations in metal and stress-strain state of welded joint and structure in whole have decisive effect on welded joint mechanical properties. These factors are determined by nature of welding heat processes. And if simulation of stationary welding process is sufficiently well described in scientific sources, then of information on calculations of heat processes in non-consumable pulse-arc welding is not enough. It is the wellknown fact that thermal-physical situation in pulse-arc welding has significant differences from that in stationary arc welding, i.e. process of heat distribution becomes non-stationary, cyclic 

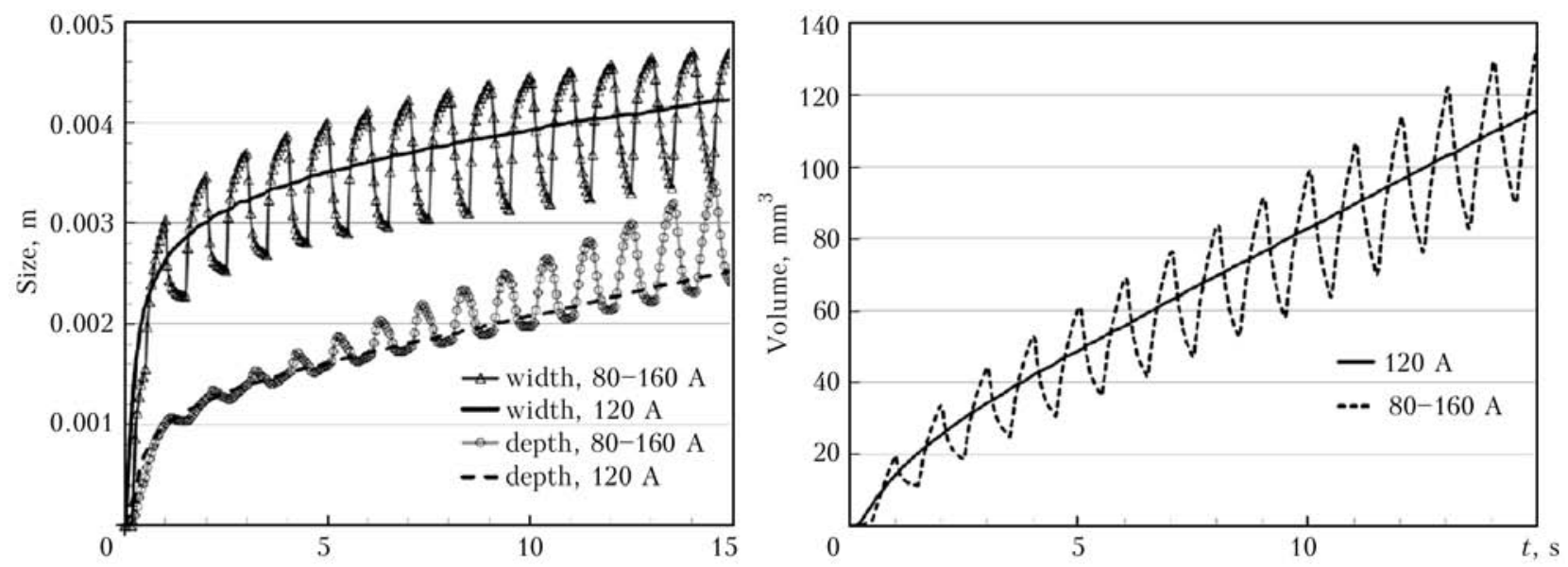

Figure 6. Comparison of geometry characteristics of weld pool for DC welding and PTIGW [36]

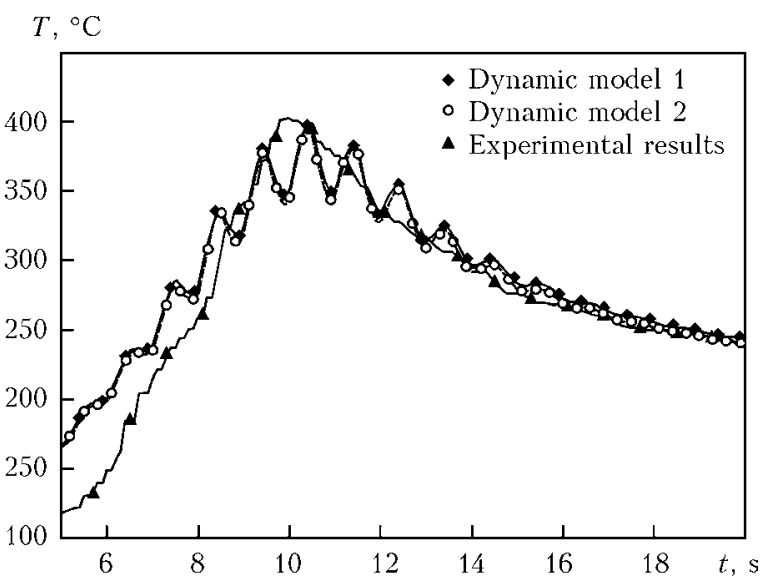

Figure 7. Welding thermal cycles, received experimentally and at FEM-simulation, for points located at $40 \mathrm{~mm}$ distance from beginning of welding, $6 \mathrm{~mm}$ from weld axis and at $4 \mathrm{~mm}$ depth for $I_{\mathrm{p}}=160 \mathrm{~A}, I_{\mathrm{b}}=80 \mathrm{~A}, f-p=1 \mathrm{~Hz}, t_{\mathrm{p}}=$ $=0.5 \mathrm{~s}$ and $t_{\mathrm{b}}=0.5 \mathrm{~s}[41]$

change of processes of heating and cooling in each point of weld and near-weld zone takes place.

Schemes of spot, linear and volumetric power sources are used for calculation of heat processes in TIG welding. The basics for calculation of heat processes in welding were founded, as everybody knows, by Rozental and Rykalin. Series of simplifications are mainly used in application of Rykalin calculation schemes for non-consumable pulse-arc welding. Works [37, 38] can be an example. Their results are rather qualitative than quantitative, and, besides, such an approach does not allow predicting the weld pool shape and it makes it inconvenient for determination of pulse welding optimum parameters.

Application of volumetric heat sources [39] is necessary for more accurate prediction of penetration depth as well as thermal condition of base metal. Procedure of FEM-simulation of heat processes is the most widely used at current time. It considers volumetric heat sources of ellipsoid form and in first approximation recall a weld pool shape [40]. Work [41] provides for the results of PTIGW simulation for heat source represented in form of parabola of rotation with normal (Gaussian) power distribution. At that, size of the source was experimentally determined, using images received with the help of speed infra-red CCD-camera. The simulation was carried out in two different statements, namely when the heat source is set in form of parabola of rotation at the moment of base current influence, and in form of Gaussian model (Figure 7, dynamic model 1) at the moment of principle current influence, as well as in the case when it is represented in form of Gaussian model for the moment of break and moment of pulse of heat source (Figure 7, dynamic model 2).

It can be seen from given thermal cycles that both dynamic models provide for satisfactory conformity with experimental thermal cycle on maximum temperatures, but that can not be said about nature of oscillation of temperatures received experimentally and mathematically. It is obvious that welding with periodic change of power, typical for PTIGW process, also promotes for periodic change of metal temperature, that can't be observed on experimental curve received by authors of work [41]. Probably, such mismatch is related with peculiarities of measurement equipment. Except for similarity of temperature calculation and experiment, an important factor is a prediction of penetration shape, that is difficult to realize using proposed procedure.

\section{Conclusion}

It is determined based on results of reference data on peculiarities of gas-shielded nonconsumableelectrode pulse-arc welding that the main problem with practical application of this method is 
absence of possibility for prediction of effect of welding mode parameters on physical and technological properties of arc discharge and, as a result, weld geometry characteristics.

It is shown that the main technological characteristic of this method of welding is mode rigidity.

It is found that such parameters of modes as current and voltage in the pulse as well as base values of current and voltage, particularly, short-term changes of energy parameters of arc discharge, have to be outlined in addition to pulse time characteristics during PTIGW analysis.

Requirements to ADT, which is used for registration of energy parameters of PTIGW process and transition processes, were formulated based on analysis of reference data and Nyquist theorem. Besides, application of synchronized video registration of pulse arc discharge is relevant for further decoding of oscillograms.

Results of simulation of physical processes in plasma and magnetic-hydro-dynamic processes in the weld pool show that various processes take place in the pool at different moments of time and they significantly depend on electrodynamic characteristics of plasma column as well as on its temperature.

Finite-element modeling of heat processes of tungsten-electrode pulse-arc welding requires application of calculation scheme of volumetric heat source of ellipsoid form and presence of calculation-experimental time dependencies of the main macroparameters for specific mathematical description of time variable of arc power.

Thus, available experimental data and results of simulation of PTIGW process reflect existence of arc discharge plasma at moments of current pulse generation and its effect on behavior of weld pool metal. Processes, accompanying appearance of the main arc discharge in pulse and its extinction, i.e. transition short-term processes, are not considered due to absence of accurate experimental data. This verifies relevance of development of optimum procedure for further investigation of these processes under PTIGW conditions, which allows development of more accurate procedure for prediction of effect of welding mode on geometry and technological characteristics of welded joint.

1. Brodsky, A.Ya. (1956) Tungsten-electrode argon-arc welding. Moscow: Mashgiz.

2. Petrov, A.V. (1961) Technology of inert-gas arc welding: Reference book on welding, Vol. 2, 327375. Ed. by E.V. Sokolov. Moscow: Mashgiz.
3. (1985) Actual problems of welding of non-ferrous metals. In: Proc. of 11th All-Union Conf. Kiev: Naukova Dumka.

4. (1985) Metals science of aluminium alloys. Ed. by S.T. Kishkin. Moscow: Nauka.

5. Russo, V.L. (1962) Inert-gas welding of aluminium alloys. Leningrad: Sudpromgiz.

6. Shakhanov, S.B. (2007) Theory and technology of welding production in rocket industry: Manual. St.Petersburg: Balt.GTU.

7. Gurevich, S.M., Zamkov, V.N., Kushnirenko, N.A. (1965) Increase of penetration efficiency of titanium alloys in argon-arc welding. Avtomatich. Svarka, 9, $1-7$.

8. Alov, A.A., Shmakov, V.M. (1962) Argon-arc welding with auxiliary argon flow. Svarochn. Proizvodstvo, 3, 13-16.

9. Terry, S.A., Tyler, W.T. (1958) Inert-gas tungstenarc welding. Welding and Metal Fabr., 2, 58-61.

10. Paton, B.E. (1963) Further development of systems of automatic control and regulation of welding processes. Avtomatich. Svarka, 5, 1-6.

11. Razmyshlyaev, A.D., Patrikeev, A.I., Maevsky, V.R (1988) Calculated definition of pool contour in stepby-step-arc welding of thick metal. Svarochn. Proizvodstvo, 5, 35-37.

12. Vagner, F.A. (1980) Equipment and methods of pulsed arc welding. Moscow: Energiya.

13. Network-based welding processes analyzing, controlling and managing. pdf. https / / www.ewm-group. $\mathrm{com} / \mathrm{ru}$ /service/downloads brochures-handoutsand-manuals / 2698-ewm-xnet-brochure/download.h tml

14. (2002) Weld+vision FRONIUS MAGAZINE, 11 pdf. http: / / www.fronius.com / cps / rde/ $\mathrm{xbcr} / \mathrm{SID}$ 76553F1D-04EC16FD/fronius brasil/4000062136 weld vision Nr 9 en.pdf

15. Petrov, A.V., Slavin, G.A. (1966) Study of technological features of pulsed arc. Svarochn. Proizvodstvo, 2, 1-4.

16. Slyvinsky, O.A., Bojko, V.P., Prepiyalo, A.O (2013) Mathematical modeling of heat processes in argon-arc welding of thin stainless steel of ferrite class. In: Proc. of 6th All-Ukr. Interbranch Sci.Techn. Conf. of Students, Post-Graduate Students and Researches on Welding and Related Processes and Technologies (Kiev, 29-31 May 2013), 14.

17. Slyvinsky, O.A., Korotenko, V.V. (2014) Mathematical modeling of heat processes of pulsed tungsten argon-arc welding of thin stainless steel. In: Proc. of 7th All-Ukr. Interbranch Sci.-Techn. Conf. of Students, Post-Graduate Students and Researches on Welding and Related Processes and Technologies (Kiev, 14-16 May 2014), 19.

18. Kovalev, I.M. (1973) Some methods for stabilizing of unstable arc with non-consumable electrode. Svarochn. Proizvodstvo, 6, 3-5.

19. Kovalev, I.M. (1972) Space stability of moving arc with non-consumable cathode. Ibid., 8, 1-3.

20. Finkelnburg, V., Mekker, G. (1961) Electric arc and thermal plasma. Moscow: IL.

21. Kozakov, Yu.M., Stolbov, V.I., Koryagin, K.B. (1986) Lagging of anode spot of moving welding arc. Svarochn. Proizvodstvo, 10, 19-21.

22. Kim, D., Rhee, S. (2001) Optimization of arc welding process parameters using a genetic algorithm. Welding J., July, 184-189.

23. Giridharan, P.K., Murugan, N. (2009) Optimization of pulsed GTA welding process parameters for welding of AISI $304 \mathrm{~L}$ stainless steel sheets. Int. J. $A d$ vanced Manufact. Technology, Issue 5, 40, 478-489.

24. Babu, S., Senthil Kumar, T. (2008) Optimizing pulsed current gas tungsten arc welding parameters of AA6061 aluminium alloy using Hooke and Jeeves algorithm. Transact. of Nonferrous Metals Soc. of China, 18, 1028-1036.

25. Chakravarthy, M.P., Ramanaiah, N., Sundara Siva Rao, B.S.K. (2013) Process parameters optimization 
for pulsed TIG welding of $70 / 30 \mathrm{Cu}-\mathrm{Ni}$ alloy welds using Taguchi technique. Int. J. Mechanical, Aerospace, Industrial, Mechatronic and Manufact. Eng., $7(4), 342-348$.

26. Arivarasu, M., Devendranath Ramkumar, K., Arivazhagan, N. (2014) Comparative studies of high and low frequency pulsing on the aspect ratio of weld bead in gas tungsten arc welded AISI $304 \mathrm{~L}$ plates. Proc. Eng., 97, 871-880.

27. Dyatlov, V.I. (1961) Volt-ampere characteristic of constricted electric arc. Avtomatich. Svarka, 1, 23-26.

28. Rabkin, D.M., Ivanova, O.N. (1968) Investigation of arc in tungsten arc welding. Ibid., 5, 16-20

29. Krivtsun, I.V., Krikent, I.V., Demchenko, V.F. (2013) Modelling of dynamic characteristics of a pulsed arc with refractory cathode. The Paton Weld ing J., 7, 13-23.

30. Zhdanov, L.A., Slyvinsky, A.M., Kotyk, V.T. et al (2003) Possibility of analog-digital converter application for study of alternating current welding arc Mashynoznavstvo, 2, 38-41.

31. Zhdanov, L.A., Slyvinsky, A.M., Kopersak, V.M. et al. (2004) Study of alternating current welding arc by personal computer. Nauk. Visti NTUU KPI, 3, 49-55.

32. Wu, C.S., Gao, J.Q. (2001) Analysis of the heat flux distribution at the anode of a TIG welding arc. Com put. Mater. Sci., 24, 323-327.

33. Lu, F., Tang, X., Yao, Yu.S. (2006) Numerical simulation on interaction between TIG welding arc and weld pool. Ibid., 35, 458-465.
34. Tanaka, M., Lowke, J.J. (2007) Predictions of weld pool profiles using plasma physics. J. Phys. D: Appl. Phys., 40, 1-23.

35. Traidia, A., Roger, F., Guyot, E. (2010) Optimal parameters for pulsed gas tungsten arc welding in partially and fully penetrated weld pools. Int. J. Therm. Sci., 49, 1197-1208.

36. Traidia, A., Roger, F. (2011) Numerical and experimental study of arc and weld pool behavior for pulsed current GTA welding. Int. J. Heat and Mass Transfer, 54, 2163-2179.

37. Petrov, A.V. (1967) Application of sources method for calculation of heat processes in pulsed-arc welding. Fizika $i$ Khimiya Obrab. Materialov, 5, 15-25.

38. Vagner, F.A. (1975) Calculation of temperatures in product during pulsed welding with exponential pulse shape. Avtomatich. Svarka, 7, 13-15.

39. Kiselev, S.N., Kiselev, A.S., Kurkin, A.S. et al. (1998) Modern aspects of computer modeling of heat, deformation processes and structure formation in welding and related technologies. Svarochn. Proizvodstvo, 10, 16-24

40. Goldak, J.A., Chakravarti, A., Bibby, M. (1984) A new finite element model for welding heat sources. Metallurg. Transact. B, Vol. 15, 229-305.

41. Zhang Tong, Zheng Zhentai, Zhao Ru (2013) A dynamic welding heat source model in pulsed current gas tungsten arc welding. J. Materials Proc. Technology, 213, 2329-2338.

Received 28.07.2015 